\title{
Hepatitis C Screening in Community-Based Voluntary Counselling and Testing Services in Europe: An Observational Study from the COBATEST Network 2014-2018
}

\author{
Anna Conway $y^{1,2}$ - Laura Fernàndez-López ${ }^{1,2,3}$. Juliana Reyes-Urueña ${ }^{1,2} \cdot$ Jordi Casabona ${ }^{1,2,3,4}$. \\ COBATEST Study Group ${ }^{1,5}$
}

Published online: 20 November 2019

(c) Springer Science+Business Media, LLC, part of Springer Nature 2019

\begin{abstract}
The COBATEST Network links community-based voluntary counselling and testing (CBVCT) services in the European region and collects testing data using standardised data collection tools. This study aims to describe the population being screened for anti-HCV antibodies in the COBATEST Network and identify risk factors associated with a reactive HCV screening test result in the period 2014-2018. Clients aged > 16 screened for HCV in the period 2014-2018 at one of the Network's CBVCT services were included in the study. In the 5 year period, 7426 clients were screened for HCV in 22 centres in 10 countries and anti-HCV antibodies were detected in $113(1.5 \%)$. The majority of people screened were aged 25-44, men who have sex with men (MSM), not HIV+, not reporting a history of injecting drug use or sex work. Detection of anti-HCV antibodies was associated with being HIV + MSM (aOR 9.1, 95\% CI 3.8; 21.8 compared to HIV-clients) and being a person who injects drugs (PWID, aOR 28.1, 95\% CI 17.6; 45.0, compared to people with no history of injecting drug use). This study demonstrates that HIV-MSM with no history of injection drug use are using CBVCT services for HCV screening, but reactive screening test is associated with being HIV+ or PWID. The integration of HCV screening into the CBVCT service model may widen access to testing for populations that may otherwise not be tested.
\end{abstract}

Keywords Hepatitis C $\cdot$ Screening $\cdot$ Community networks $\cdot$ Europe

The COBATEST Study Group members are listed in

Acknowledgement section.

Electronic supplementary material The online version of this article (https://doi.org/10.1007/s10900-019-00780-0) contains supplementary material, which is available to authorized users.

Anna Conway

aconway@igtp.cat

1 Generalitat de Catalunya Departament de Salut, Centre Estudis Epidemiologics sobre les Infeccions de Transmissio Sexual i Sida de Catalunya (CEEISCAT), Barcelona, Catalunya, Spain

2 L'Institut de Recerca en Ciències de la Salut Germans Trias i Pujol, Badalona, Catalonia, Spain

3 CIBERESP, CIBER Epidemiologia y Salud Publica, Barcelona, Catalunya, Spain

4 Department of Paediatrics, Obstetrics and Gynecology and Preventive Medicine, Universitat Autonoma de Barcelona, Barcelona, Catalunya, Spain

5 AIDS Action Europe, c/o Deutsche AIDS-Hilfe, Wilhelmstr 138, 10963 Berlin, Germany

\section{Introduction}

In 2017, 31,273 cases of hepatitis C virus (HCV) were reported to the ECDC in 29 EU/EEA Member States, corresponding to a crude rate of 7.3 cases per 100,000 population [1]. These figures are likely to be an underestimate as hepatitis infection often shows no symptoms. Only $26.0 \%$ of the cases in 2017 included data on the mode of transmission, the most common of which was injecting drug use accounting for $44.0 \%$ of those cases with complete information on transmission status [1]. WHO in 2016 recommended a dramatic scale-up of $\mathrm{HCV}$ testing and linkage to care to achieve elimination of HCV by 2030 [2]. HCV screening and treatment interventions carry a double public health benefit: reducing both morbidity and incidence through a treatment-as-prevention effect [3].

A recent scoping review of studies investigating barriers to $\mathrm{HCV}$ testing, found that low self-perceived risk of acquiring $\mathrm{HCV}$, perceived stigma and fear of a positive result were reported as barriers to HCV screening 
and testing. There are also barriers to providers wishing to offer HCV screening, including time constraints, lack of specific knowledge about HCV and discomfort in asking about risk behaviours [4]. Peer counselling offered in community-based voluntary counselling and testing (CBVCT) services can help men who have sex with men (MSM) overcome additional barriers to testing such as homophobia and internalised homonegativity [5]. The WHO recommends that CBVCT services form part of a country's national testing strategy, including testing by trained non-medical professionals. Many CBVCT services, recognising the needs of their clients, have moved beyond HIV screening and now offer screening for $\mathrm{HCV}$ and syphilis [6].

WHO guidelines state that rapid diagnostic tests have acceptable sensitivity and specificity compared to laboratory-based testing and can be successful at increasing testing uptake and reducing loss to follow-up (World Health Organization (WHO) [7]). Once the rapid diagnostic test performed in CBVCT services detects anti-HCV, a HCV RNA nucleic acid test has to be performed to establish active $\mathrm{HCV}$ infection and ensure linkage to care.

The COBATEST Network links organisations across Europe who offer CBVCT services and promotes testing, early diagnosis and linkage to care in at-risk populations. Services are heterogenous, variously targeting the general population or mix of key populations; (MSM), people who inject drugs (PWID), migrants or sex workers (SW). Clients enter CBVCT services seeking an anonymous and confidential HIV, hepatitis C or syphilis screening. Not all services offer testing for all diseases. The HCV screening tests detect antibodies to $\mathrm{HCV}$ in human serum, plasma or whole blood (giving result: reactive/unreactive). Clients with a reactive specimen then require referral for an RNA test to identify current $\mathrm{HCV}$ infection (giving result: active $\mathrm{HCV}$ infection/no active HCV infection). RNA testing is not part of the standard offer for CBVCT services but they can report to the COBATEST data collection tool if they have the result of the RNA test performed at another site. The COBATEST Network began in 2013 with the goal of homogenizing the monitoring and evaluation of HIV testing activities at the community level $[8,9]$ and later expanded to syphilis and HCV screening. The standardised data collection tools collect information on sociodemographic characteristics, reasons for testing, previous HIV/ $\mathrm{HCV} /$ syphilis screening testing, risk behaviours, HIV/ $\mathrm{HCV} /$ syphilis screening test results, linkage to care. Since 2014 this data has been collected and centralised in a single database. In 2018, 45 organisations in 20 countries in the WHO European region submitted data on their testing activity.

This study is the first pan-European observational study using data from CBVCT services which share common data collection tools to investigate screening for $\mathrm{HCV}$ in a range of populations. Using COBATEST data, this study aims to understand who is using CBVCT services for $\mathrm{HCV}$ screening and what factors determine a reactive test. This study describes HCV screening activity in CBVCT services, describes the populations being screened, describes the proportion of reactive HCV screening tests and identifies risk factors associated with a reactive HCV screening test result in the COBATEST Network in the years 2014-2018.

\section{Methods}

This study is based on disaggregated data collected from members of the COBATEST Network which offered HCV screening for a minimum of 6 months during the period of study (January 1st 2014-December 31st 2018). Counsellors complete pre-test counselling and collect information on the client using the COBATEST standardised data collection tools. COBATEST network members can submit their data in one of three ways: using the online COBATEST tool; in disaggregated format according to data file specifications; in aggregated format with the COBATEST indicators already calculated. For this study, all disaggregated data submitted before the censuring date of 28 February 2019 was included. CBVCT services use a unique Client Identification Code to anonymise the client data and allow the identification of repeat testers. In the case that one person was screened multiple times for HCV over the study period, only the most recent HCV screening test was included in the study. Those with no reported HCV screening test result or aged under 16 were removed from the analysis. The flowchart of inclusion criteria is presented in Fig. 1. The same inclusion criteria were applied to people tested for HIV, not HCV, in the COBATEST Network and a comparison between the two groups is presented in Online Annex 1.

Firstly, we described characteristics and activity in CBVCT services which offer HCV screening. To do this we used an existing database created as part of a 2017 study into the quality of the COBATEST Network's data [10]. In the scope of that study, all the CBVCT services that were partners of the COBATEST Network in 2017 were invited to complete the online survey which was a piloted, structured ad hoc instrument hosted by the Survey Monkey website. CBVCT services that did not send the information in 2017 were contacted for this study via email to report their services' characteristics. We refer to each CBVCT service by its number which is randomly assigned when a service joins the COBATEST Network. According to CBVCT service, we report testing setting, target population, which HCV screening tests were offered (rapid oral test, rapid blood test, conventional test) and number of people screened for HCV. 
Fig. 1 Flowchart of inclusion criteria for participation in study of HCV testing in the COBATEST network 2014-2018

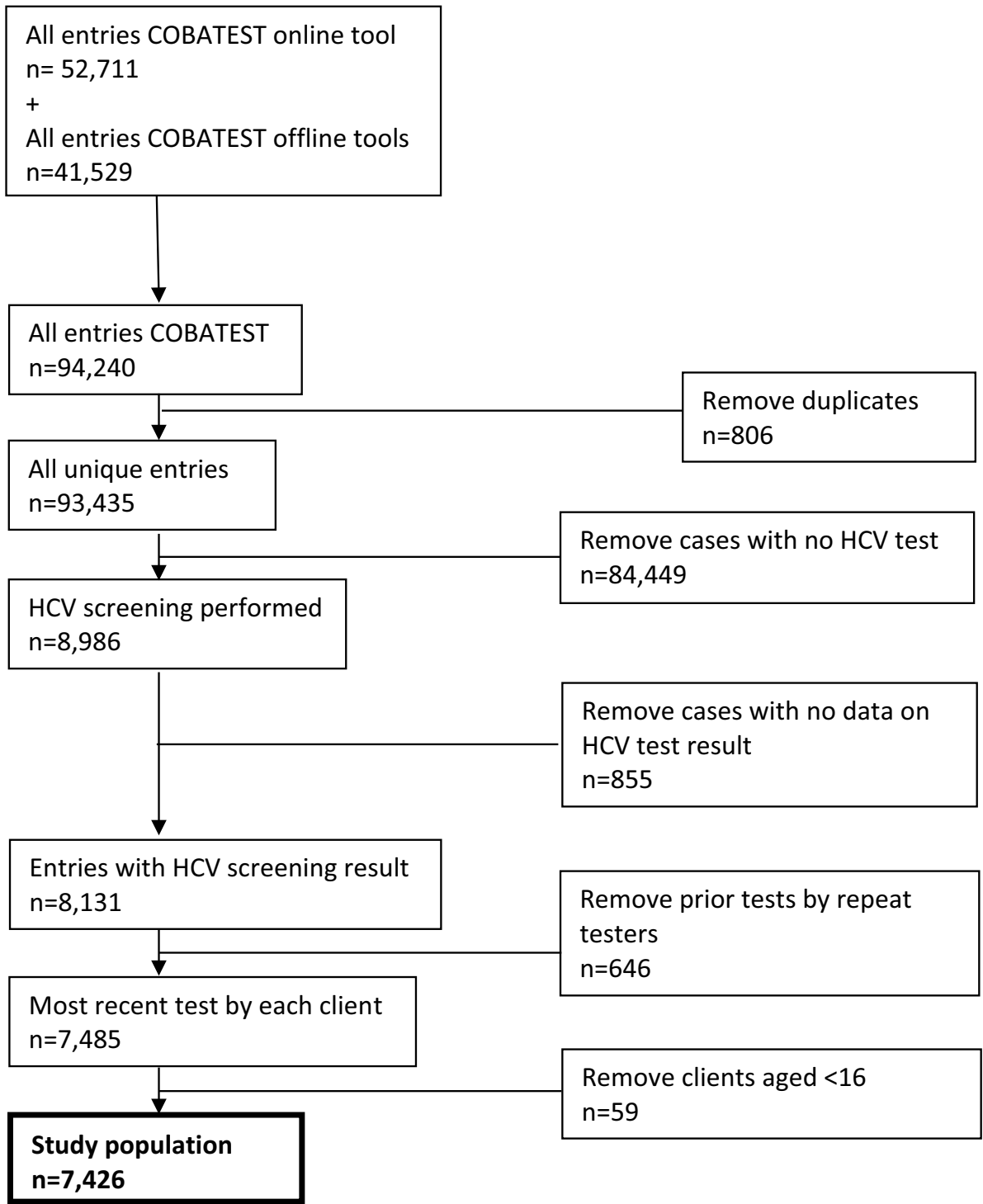

Secondly, the clients screened for HCV and clients with a reactive screening test were described by socio-demographic characteristics (gender [men, women, transgender], age group [16-24, 25-44, 45-64, > 65], migrants [defined as been born in a country different to the country where the CBVCT service is placed], region of origin), key populations (MSM, PWID, SW) and epidemiological variables (HIV status, HCV screening test results and RNA test results). Differences between groups were assessed using the Pearson's $\mathrm{Chi}^{2}$ test with a $\mathrm{p}$ value of $<0.05$ considered statistically significant.

Finally, the univariate logistic regression analysis was performed and the odds ratios for a reactive HCV screening test were presented with their $95 \%$ confidence intervals and $\mathrm{p}$ values. Clients with missing information on key populations were considered in the non-risk category (see below for sensitivity analysis). The multivariate logistic regression model was decided using a forwardstepwise method, using the significant variables from the univariate analysis. In the case that two variables that were both significant in the univariate analysis showed colinearity, the one likely to be a bigger contributor to $\mathrm{HCV}$ incidence according to the literature was selected for the forward-stepwise method. For example, if the variables $\mathrm{HIV}+\mathrm{MSM}$ and MSM were both significantly associated with reactive $\mathrm{HCV}$ test, MSM was discarded when selecting variables for the multivariate model.

There were high proportions of missing data in some variables included in the logistic regression model. A sensitivity analysis was performed to understand the impact of recoding missing data to the non-risk category in the logistic regression model. The results from the analysis of two different logistic 
regression models were compared; the first (the model used for this study) considered all missing and "don't know" responses in the non-risk category and the second eliminated all missing and "don't know" answers from the analysis.

Data analysis was performed using StataSE 14.1.

\section{Results}

The description of COBATEST members in Table 1 shows the heterogeneity of their services; testing is variously offered on-site, in outreach or in venues using rapid oral test, rapid blood test or conventional laboratory tests. The majority of centres target the general population or MSM. The services are not representative, neither at the national nor European level, of CBVCT services offering HCV screening.

In the 5 year period, 7426 clients were screened for $\mathrm{HCV}$ in 21 centres in 10 countries and 113 had a reactive result $(1.5 \%$, range $0.0-15.5 \%)$. In the first year of the study (2014), the number of centres submitting data on HCV screening was 6 and the number of tests was 81 . In the last year of the study (2018) this rose to 18 centres and 3917 tests. The proportion of reactive HCV screening tests was $4.9 \%$ in the first year of the study, dropping to $1.2 \%$ in the last year. During the period of study, seven COBATEST members had no reactive results. The CBVCT service with the highest proportion of reactive test results is the only one which has a target population of PWID. Of the 113 clients with reactive screening test, $95(84.1 \%)$ had no information on RNA test result, $16(14.2 \%)$ reported active infection ( 2 of those were HIV + MSM) and 2 (1.8\%) reported no current HCV infection (Not displayed).

Table 2 describes the testers; the majority aged $\geq 25$ and $<45$, MSM, not HIV+, not reporting a history of injecting drug use or sex work. Of the 75 persons reporting to be HIV+, 68 were MSM (not displayed). The proportion of reactive HCV screening test was higher in transgender people compared to men and women (not statistically significant), higher in people living with HIV (PLHIV) than others, higher in sex workers (SW) than non-sex workers and higher in PWID than those not reporting history of injecting drug use. Missing data is displayed as a percentage of each variable. More than $80 \%$ of information was complete for each of the following variables: gender, migrant, MSM. Other variables were less complete: age group ( $77.6 \%$ complete), sex worker ( $64.2 \%$ complete) result of last HIV test (51.9\% complete) (Table 2).

Table 3 presents the results of the univariate and multivariate logistic regression analysis. A reactive $\mathrm{HCV}$ screening test result was associated with being aged $\geq 25$ and $<45$, MSW, PWID; a migrant or a PLHIV. For the multivariate model, age was excluded given the large proportion of missing data. The final multivariate model included HIV + MSM, PWID and migrant status, finding each to be independently associated with a reactive $\mathrm{HCV}$ screening test.

The results of the sensitivity analysis are presented in Online Annex 1. The factors associated with a reactive HCV screening test remained the same in both models and the strength of the association differed only slightly indicating that considering the missing responses in the non-risk category did not greatly impact the results of the study.

\section{Discussion}

This study demonstrates that HIV- MSM with no history of injection drug use are using CBVCT services for $\mathrm{HCV}$ screening, but a reactive screening test is associated with being HIV+ or PWID. CBVCT services in the European region are increasingly integrating $\mathrm{HCV}$ screening into their service model to ensure testing is more widely available for populations that may otherwise not be tested. The use of standardised data collection tools in the COBATEST network allows for HCV screening data to be pooled and analysed in a timely and robust manner. The study identifies client characteristics associated with a reactive HCV screening test which could assist CBVCT services in targeting testing.

The number of CBVCT services in the COBATEST Network offering HCV testing and the number of tests performed has increased every year since 2014 but the large numbers of HIV tests carried out over the study period shows that this is still services' main testing activity (see Fig. 1). Although this sample is not representative of all CBVCT services in Europe or CBVCT services in each country, it may reflect the increasing number of CBVCT services offering HCV screening. The rising number of tests performed in the network comes with a decrease in proportion of reactive $\mathrm{HCV}$ tests, reflecting services increasingly offering screening to populations at low risk of HCV. This could have implications for the cost-effectiveness of CBVCT services and requires more investigation to understand how services fund their $\mathrm{HCV}$ screening programme and to understand if CBVCT services have the knowledge to identify people at higher risk of $\mathrm{HCV}$.

Services offered by COBATEST members are heterogeneous but the majority of clients being screened for $\mathrm{HCV}$ are MSM, as has been seen in previous studies on HIV screening [8]. We found a high proportion of reactive $\mathrm{HCV}$ tests in PWID, in line with the lower end of the estimated range from the ECDC (7-95.4\%) [11]. The low number of PWID tested reflects the fact that PWID are not the target population for the majority of the CBVCT services in this study. PWID could benefit from improved access to services 


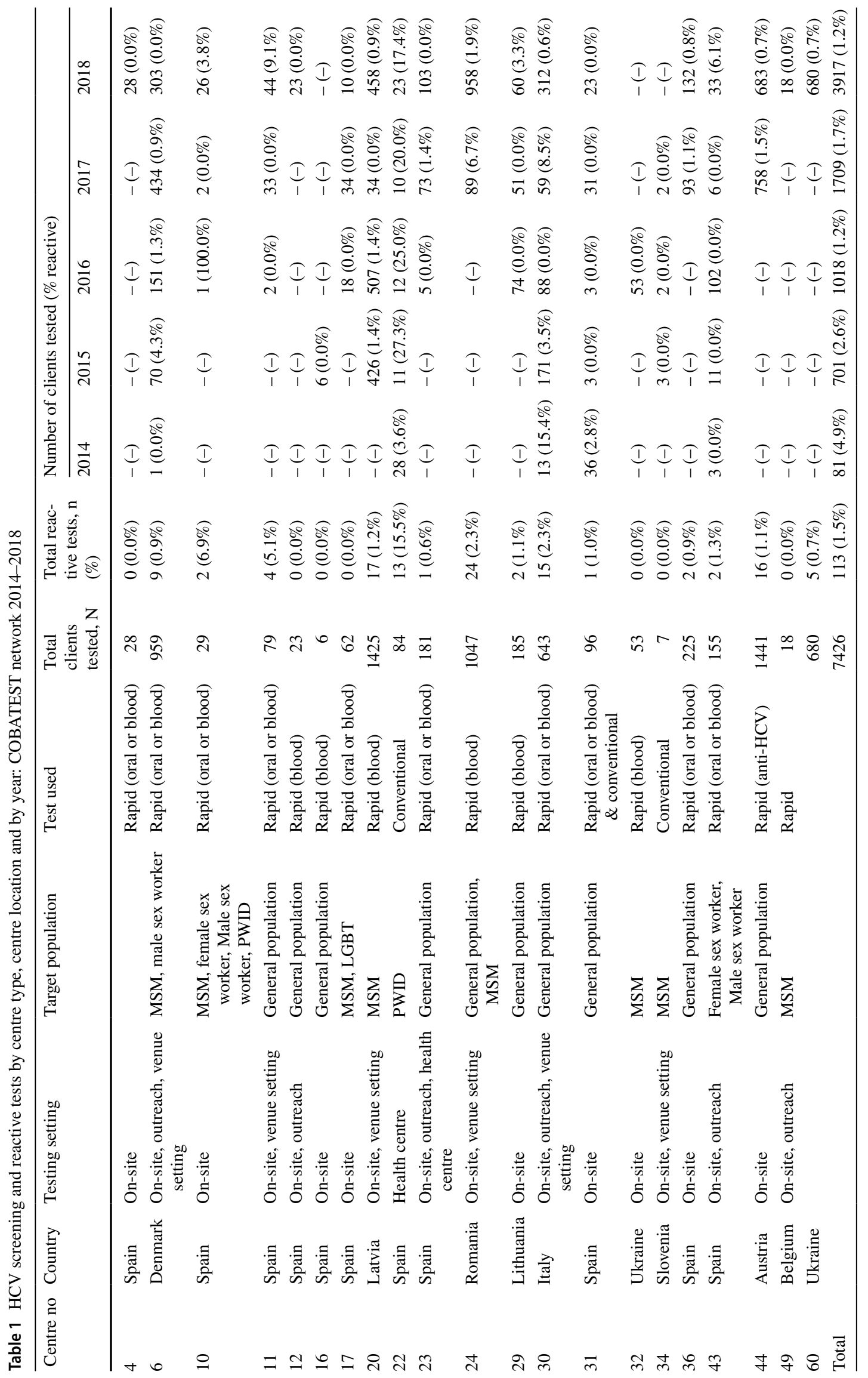


Table 2 Description of $\mathrm{HCV}$ screening tests by sociodemographic variables and risk behaviours: COBATEST Network 2014-2018

\begin{tabular}{|c|c|c|c|c|c|}
\hline & \multicolumn{2}{|c|}{ Non-reactive } & \multicolumn{2}{|c|}{ Reactive } & \multirow[t]{2}{*}{$\mathrm{p}$ value $^{\mathrm{a}}$} \\
\hline & $\mathrm{N}$ & $\begin{array}{l}\% \text { non-reactive in } \\
\text { each category }\end{array}$ & $\mathrm{n}$ & $\begin{array}{l}\text { \% reactive in each } \\
\text { category }\end{array}$ & \\
\hline Total & 7313 & 98.5 & 113 & 1.5 & \\
\hline \multicolumn{6}{|l|}{ Gender } \\
\hline Male & 5642 & 98.6 & 82 & 1.4 & \\
\hline Female & 1563 & 98.2 & 29 & 1.8 & \\
\hline Transgender & 103 & 98.1 & 2 & 1.9 & \\
\hline Missing & 5 & 100.0 & 0 & 0.0 & 0.7 \\
\hline \multicolumn{6}{|l|}{ Age group } \\
\hline$\geq 16$ and $<25$ & 1695 & 99.2 & 13 & 0.8 & \\
\hline$\geq 25$ and $<45$ & 3188 & 97.9 & 69 & 2.1 & \\
\hline$\geq 45$ and $<65$ & 730 & 98.3 & 13 & 1.7 & \\
\hline$\geq 65$ & 56 & 98.2 & 1 & 1.8 & \\
\hline Missing & 1644 & 99.0 & 17 & 1.0 & 0.002 \\
\hline \multicolumn{6}{|l|}{ Migrant } \\
\hline Yes & 1403 & 97.5 & 36 & 2.5 & \\
\hline Sub-saharan Africa & 116 & 99.1 & 1 & 0.9 & \\
\hline North Africa & 43 & 93.5 & 3 & 6.5 & \\
\hline North America & 29 & 100.0 & 0 & 0.0 & \\
\hline Latin America \& Caribbean & 207 & 98.1 & 4 & 1.9 & \\
\hline Asia & 158 & 95.8 & 7 & 4.2 & \\
\hline Australasia & 10 & 100.0 & 0 & 0.0 & \\
\hline Europe & 487 & 96.2 & 19 & 3.8 & \\
\hline Migrants missing region of origin & 353 & 99.4 & 2 & 0.6 & \\
\hline No & 4855 & 98.7 & 66 & 1.3 & \\
\hline Missing migrant status & 1055 & 99.0 & 11 & 1.0 & $0.007 *$ \\
\hline \multicolumn{6}{|l|}{ MSM } \\
\hline Yes & 62 & 99.0 & 42 & 1.0 & \\
\hline No & 5287 & 97.8 & 62 & 2.2 & \\
\hline Missing & 1964 & 98.1 & 9 & 1.9 & 0.001 \\
\hline \multicolumn{6}{|l|}{ Sex worker } \\
\hline Yes & 320 & 97.0 & 10 & 3.0 & \\
\hline Male & 153 & 98.7 & 2 & 1.3 & \\
\hline Female & 107 & 94.7 & 6 & 5.3 & \\
\hline Transgender & 60 & 96.8 & 2 & 3.2 & \\
\hline No & 4360 & 98.3 & 76 & 1.7 & \\
\hline Missing & 2633 & 99.0 & 27 & 1.0 & $0.001 *$ \\
\hline \multicolumn{6}{|l|}{ PWID } \\
\hline Yes & 96 & 75.6 & 31 & 24.4 & \\
\hline No & 4774 & 98.7 & 61 & 1.3 & \\
\hline Missing & 2443 & 99.1 & 15 & 0.9 & $<0.001$ \\
\hline \multicolumn{6}{|l|}{$\mathrm{HIV}+$} \\
\hline Yes & 68 & 90.7 & 7 & 9.3 & \\
\hline No & 3717 & 98.3 & 64 & 1.7 & \\
\hline Missing & 3528 & 98.8 & 42 & 1.2 & $<0.001$ \\
\hline \multicolumn{6}{|l|}{ MSM HIV+ } \\
\hline Yes & 62 & 91.2 & 6 & 8.8 & \\
\hline No & 5287 & 98.4 & 87 & 1.6 & \\
\hline Missing & 1964 & 99.0 & 20 & 1.0 & $<0.001$ \\
\hline
\end{tabular}

$M S M$ men who have sex with men, $F S W$ female sex worker, $M S W$ male sex worker, $T S W$ transgender sex worker, $P$ WID people who inject drugs

*Comparing categories: yes, no, missing

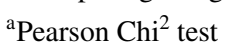


Table 3 Odds of a reactive HCV screening test by sociodemographic variables and risk behaviours: COBATEST Network 2014-2018

\begin{tabular}{|c|c|c|c|c|c|c|}
\hline & $\mathrm{cOR}$ & $95 \% \mathrm{CI}$ & $\mathrm{p}$ & $\mathrm{aOR}$ & $95 \% \mathrm{CI}$ & $\mathrm{p}$ \\
\hline \multicolumn{7}{|l|}{ Gender } \\
\hline \multicolumn{7}{|l|}{ Male } \\
\hline Female & 1.3 & $(0.8 ; 2.0)$ & 0.26 & & & \\
\hline Transgender & 1.3 & $(0.3 ; 5.5)$ & 0.69 & & & \\
\hline \multicolumn{7}{|l|}{ Age group } \\
\hline \multicolumn{7}{|l|}{$\geq 16$ and $<25$} \\
\hline$\geq 25$ and $<45$ & 2.8 & $(1.6 ; 5.1)$ & $<0.001$ & & & \\
\hline$\geq 45$ and $<65$ & 2.3 & $(1.1 ; 5.0)$ & 0.03 & & & \\
\hline$\geq 65$ & 2.3 & $(0.3 ; 18.1)$ & 0.42 & & & \\
\hline \multicolumn{7}{|l|}{ Migrant } \\
\hline \multicolumn{7}{|l|}{ No } \\
\hline Yes & 2.0 & $(1.3 ; 2.9)$ & 0.001 & 1.6 & $(1.0 ; 2.4)$ & 0.04 \\
\hline \multicolumn{7}{|l|}{ MSM } \\
\hline \multicolumn{7}{|l|}{ No } \\
\hline Yes & 0.5 & $(0.3 ; 0.7)$ & $<0.001$ & & & \\
\hline \multicolumn{7}{|l|}{ Sex worker } \\
\hline \multicolumn{7}{|l|}{ No } \\
\hline FSW & 0.9 & $(0.2 ; 3.6)$ & 0.87 & & & \\
\hline MSW & 3.8 & $(1.6 ; 8.9)$ & $<0.001$ & & & \\
\hline TSW & 2.3 & $(0.5 ; 9.4)$ & 0.26 & & & \\
\hline \multicolumn{7}{|l|}{ PWID } \\
\hline \multicolumn{7}{|l|}{ No } \\
\hline Yes & 28.4 & $(17.9 ; 45.0)$ & $<0.001$ & 28.1 & $(17.6 ; 45.0)$ & $<0.001$ \\
\hline \multicolumn{7}{|l|}{ HIV+ } \\
\hline \multicolumn{7}{|l|}{ No } \\
\hline Yes & 7.0 & $(3.2 ; 15.7)$ & $<0.001$ & & & \\
\hline \multirow{2}{*}{\multicolumn{7}{|c|}{$\begin{array}{l}\text { MSM HIV+ } \\
\text { No }\end{array}$}} \\
\hline & & & & & & \\
\hline Yes & 6.6 & $(2.8 ; 15.5)$ & $<0.001$ & 9.1 & $(3.8 ; 21.8)$ & $<0.001$ \\
\hline
\end{tabular}

$M S M$ men who have sex with men, $F S W$ female sex worker, $M S W$ male sex worker, $T S W$ transgender sex worker, $P W I D$ people who inject drugs, $c O R$ crude odds ratio, $a O R$ adjusted odds ratio, CI confidence interval offering HCV screening which are tailored to their needs. Peer counselling for this group has been suggested as a way to destigmatise testing [12].

In this study, being MSM was not associated with a reactive $\mathrm{HCV}$ screening test but being HIV + MSM was. $\mathrm{HIV}+\mathrm{MSM}$ account for a small fraction of all people tested but show a high proportion of reactive tests, reflecting studies that find the HCV burden in MSM is concentrated in HIV + MSM [13]. The COBATEST questionnaire does not collect enough information to identify other subpopulations of MSM at higher risk of HCV such as preexposure prophylaxis (PrEP) users. A study in France in 2016-early 2017 found the incidence of primary HCV in HIV + MSM similar to that of HIV-MSM who use PrEP and recommends both groups should be targeted for $\mathrm{HCV}$ screening (Cotte et al. [14]. ECDC public health guidance for HCV testing recommends that MSM, trans people and SW be tested for HCV every 6-12 months depending on ongoing risk (sexualised drug use, PrEP or PEP use, HIV infection, history of rectal bacterial STI), that PWID be tested up to every 6 months and migrants be tested once with re-testing based on individual risk assessment [15]. To assess clients' ongoing risk, from the beginning of 2019 the COBATEST data collection tool will collect information on PrEP use and chemsex.

There are several limitations to this study. The study includes services in 10 countries but the results are not representative of all CBVCT activity in these countries, nor in the European region, and therefore cannot be generalised to the region. We do not have complete information on how centres select who to screen for $\mathrm{HCV}$, and why over 84,000 clients were screened for HIV and not HCV. There was a high proportion of missing data for some variables but, according to the sensitivity analysis, 
the estimated effect of this was minimal. There are issues with the data quality and documentation at service level which have been identified in a recent study [10] and have not all yet been resolved. CBVCT services offer anonymous and confidential screening services, and no on-site RNA test, thus it is unsurprising that there is a high percentage of missing information on RNA tests. In order to understand if CBVCT services are diagnosing active $\mathrm{HCV}$ infections, the reporting of RNA tests and results should be improved. This could be achieved by collaborating with local infectious disease clinics or laboratories to share RNA test results with the consent of the client. Further investigation is needed to understand if CBVCT services have functional linkage to care pathways for clients with a reactive $\mathrm{HCV}$ screening test.

This study shows that the CBVCT service model can be used to screen for HCV and that services are detecting possible active $\mathrm{HCV}$ infection. CBVCT services that historically focussed on HIV testing are now expanding to offer screening for HCV and other diseases. This could boost testing coverage, especially for key populations, which is an essential element of any European country's strategy to eliminate HCV. Countries should incorporate the CBVCT service model as part of a national strategy to increase $\mathrm{HCV}$ diagnosis and linkage to care in order to reduce the burden of disease. Governments can support CBVCT services by facilitating circuits that allow fast referral to an RNA test for clients who have had a reactive $\mathrm{HCV}$ screening and ensure linkage to care for those with an active infection.

Acknowledgements We thank the following for taking the time to review the manuscript: Cristina Agusti Benito (CEEISCAT), Julia Becerril Gascón (CASDA-Asociació Ciutadana Contra la SIDA), Valentin Blaison (ExAequo), Patricia Colomera (CAS/ARDS Lluís Companys), Lella Cosmaro (LILA Milano), Sabrina Penon (LILA Milano), Heidi Slavin (AIDS Fondet). We thank all organisations who form part of the COBATEST Network and carry out testing activities throughout the year (organisations whose data is included in this study are marked with an asterix): Associació Antisida Lleida (Spain), Abraco (Portugal), Asociación Comunitaria Anti Sida de Girona (Spain), Associació Ciutadana Antisida de Catalunya (Spain), Associació Ciutadana Alacant i província de persones afectades VIH (Spain)* $^{*}$, Asociación Ciudadana Cántabra Anti Sida (Spain), Actuavallès (Spain)*, Adhara (Spain), AIDES (France), AIDS Fondet (Denmark)*, AIDS Hilfe Wien (Austria)*, Alliance Global (Ukraine)*, Àmbit Prevenció (Spain)*, ARAS (Romania)*, AIDS Solidarity Movement Cyprus (Cyprus), Asociación Somos LGT (Spain)*, Asocijacija Duga (Serbia), Assexora'Tgn (Spain)*, Associació Lambda (Spain)*, AVACOS-H (Spain)*, Baltic HIV Associati (Latvia)*, CAS/ARDS Lluís Companys (Spain)*, Asociación Ciudadana Contra el SIDA Castellón-CASDA (Spain)*, Comité Ciudadano Antisida de Asturias (Spain), Centre Jove d'Antico (Spain), Checkpoint Milano (Italy), Creu Roja Tarragona (Spain), Czech AIDS Help (Czech Republic), Demetra (Lithuania)*, Deutsche AIDS Hilfe (Germany), Ex Aequo (Belgium)*, Fondazione LILA Milano (Italy)*, Fulcrum (Ukraine)*, Gais Positius (Spain)*, GAT Portugal (Portugal), GenderdocM (Moldova), Health Without Borders (Bulgaria), HERA (Macedonia), HUHIV (Croatia),
Iskorak (Croatia), LaSky (Russia), Legebitra (Slovenia)*, Mujer Gades (Spain), National AIDS Centre (Poland), OMSIDA (Spain)*, StopSida (Spain), Swiss Checkpoints (Switzerland).

Funding The COBATEST Network received grants from Gilead Sciences Europe Ltd (2017) and the Health Programme of the European Union (2018-2019) during the study.

\section{Compliance with Ethical Standards}

Conflict of interest There are no conflict of interest for any author.

\section{References}

1. European Centre for Disease Prevention and Control. (2019). Annual epidemiological report for 2017-Hepatitis C.

2. World Health Organisation. (2016). Combating hepatitis B and $C$ to reach elimination by 2030.

3. Heffernan, A., Cooke, G. S., Nayagam, S., Thursz, M., \& Hallett, T. B. (2019). Scaling up prevention and treatment towards the elimination of hepatitis $\mathrm{C}$ : A global mathematical model. The Lancet, 6736(18), 1-12. https://doi.org/10.1016/S0140 $-6736(18) 32277-3$.

4. Shehata, N., Austin, T., Ha, S., \& Timmerman, K. (2018). Barriers to and facilitators of hepatitis $\mathrm{C}$ virus screening and testing: A scoping review. Can Commun Dis Rep, 44(6), 166-172.

5. Ross, M. W., Berg, R. C., Schmidt, A. J., Hospers, H. J., Breveglieri, M., Furegato, M., et al. (2013). Internalised homonegativity predicts HIV-associated risk behavior in European men who have sex with men in a 38-country cross-sectional study: Some public health implications of homophobia. British Medical Journal Open, 3(2), 1-11. https://doi.org/10.1136/bmjopen-2012-001928.

6. Conway, A., \& Fernàndez López, L. (2018). COBATEST network: Community-based voluntary counselling and testing in Europe 2017 Report.

7. World Health Organization (WHO). (2017). WHO guidelines on hepatitis $B$ and $C$ testing.

8. Fernàndez-López, L., Reyes-Urueña, J., Agustí, C., Kustec, T., Klavs, I., \& Casabona, C. (2016). The COBATEST network: A platform to perform monitoring and evaluation of HIV community-based testing practices in Europe and conduct operational research. AIDS Care, 0121, 1-5. https://doi.org/10.1080/09540 121.2016.1146218.

9. Klavs, I., Kustec, T., Fernàndez López, L., Casabona, J., Meulbroek, M., Rios, L., \& Al, E. (2014). Guidelines for data collection for monitoring and evaluation of community based voluntary counselling and testing (CBVCT) for HIV in the COBATEST network.

10. Reyes-Urueña, J., Fernàndez-Lopez, L., Montoliu, A., Conway, A., Tavosch, L., Klavs, I., ... Network, T. C. (2019). Assessing the quality of routine HIV testing data in the community setting 'COBATEST Network.' International Journal of STD and AIDS. https://doi.org/10.1177/0956462419857572

11. European Centre for Disease Prevention and Control. (2018a). Hepatitis $B$ and C epidemiology in selected population groups in the EU/EEA.

12. Schatz, E., Schiffer, K., Maher, M., Harris, M., Roca, X. M., Maticic, M., et al. (2016). The Berlin Hepatitis C Manifesto: access to prevention, testing, treatment and care for people who use drugs. Hepatology, Medicine and Policy, 1(1), 1-9. https://doi. org/10.1186/s41124-016-0021-9. 
13. MacGregor, L., Martin, N. K., Mukandavire, C., Hickson, F., Weatherburn, P., Hickman, M., et al. (2017). Behavioural, not biological, factors drive the HCV epidemic among HIV-positive MSM: HCV and HIV modelling analysis including HCV treatment-as-prevention impact. International Journal of Epidemiology, 46(5), 1582-1592. https://doi.org/10.1093/ije/dyx075.

14. Cotte, L., Cua, E., Reynes, J., Raffi, F., Rey, D., Delobel, P., ... Dat'AIDS study Group. (2018). Hepatitis C virus incidence in HIV-infected and in preexposure prophylaxis (PrEP)-using men having sex with men. Liver International. https://doi.org/10.1111/ liv. 13922
15. European Centre for Disease Prevention and Control. (2018). Public health guidance on HIV, hepatitis B and C testing in the EU/ EEA-An integrated approach.

Publisher's Note Springer Nature remains neutral with regard to jurisdictional claims in published maps and institutional affiliations. 